\title{
Taking a Look at the Heath Sciences and Technology Academy (HSTA): Student-Research Partnership Increases Survey Size, Hands-on STEM Learning, and Research-Community Connections
}

\author{
Paul Siciliano1, Bethany Hornbeck², Sarah Hanks ${ }^{3}$, Summer Kuhn ${ }^{3}$, Alicia Zbehlik ${ }^{4}$, and Ann L. Chester ${ }^{3,5}$ \\ ${ }^{1}$ Pittsburg, PA; ${ }^{2}$ Grafton, WV; ${ }^{3}$ HSTA; ${ }^{4}$ Dartmouth Institute for Health Policy and Clinical Practice; ${ }^{5}$ West Virginia University, Morgantown, WV \\ Keywords: Community research partnership, underrepresented youth, rural populations, health disparities \\ Publication Date: January 26, 2018 \\ DOI: https://doi.org/10.15695/jstem/v1i1.7
}

\begin{abstract}
This paper explores the dynamics of a research partnership between a practicing clinician/research and 34 West Virginia high school students participating in a precollege STEM intervention program. The collaboration provided a more diverse study sample to the clinician for examining attitudes about knee osteoarthritis in adults over 40. It provided students the opportunity to collect data from adults in their community within a highly structured research project and explore a range of research questions using the resulting cross-state data set. Data collection far surpassed the researcher's expectations of 100 surveys; student researchers collected 1,129 unique surveys over nine months from difficult to reach Appalachian communities. This project illustrates the intervention program's ability to support partner research efforts while opening the STEM pipeline to under-served youth by introducing aspects of community-based participatory research (CBPR) pathways to them in their formative years.
\end{abstract}

\section{INTRODUCTION}

The Health Sciences and Technology Academy (HSTA) is a historically successful science, technology, engineering, and math (STEM) education pro-gram founded in 1994 in West Virginia to help underrepresented West Virginia youth successfully transition from high school to college and into the STEM workforce (Chester and Dooley, 2011; McKendall et al., 2000). The HSTA structure includes a mechanism that permits students to form partner-ships with professional researchers in conducting community-based participatory research (CBPR) in Appalachian communities throughout the state. CBPR is a research approach that equitably partners community members, organizational representatives, researchers, and other stakeholders in all aspects of the research process. Partners contribute expertise and share decision making and ownership. The primary objective of CBPR is to increase knowledge and understanding of a given phenomenon and integrate the knowledge gained with intervention, as well as policy and social change, to improve the health and quality of life of community members (Israel et al., 1998; Israel, 2008).

This paper explores the dynamics of the partnering process through a 2014-15 collaboration between HSTA and Dr. Alicia Zbehlik, a rheumatologist with an interest in osteoar- thritis (OA), assistant professor on the faculty of the Geisel School of Medicine at Dartmouth College, and a researcher funded by the Dartmouth Institute for Health Policy and Clinical Practice in Hanover, New Hampshire. Through the collaboration, Dr. Zbehlik found a unique opportunity to access difficult-to-reach populations via HSTA's long-standing ties with the communities it serves throughout West Virginia.

An Opportunity for Collaboration. Dr. Zbehlik was interested in finding ways to improve outcomes of OA care through increased activity and weight loss. Knee OA is a leading cause of mobility impairment in the United States, and its associated costs are staggering. In 2011, they reached $\$ 14.8$ billion dollars, making OA the second-most expensive hospital-treated condition that year (Stranges et al., 2008). Our nation's aging population and rising obesity rates contribute to the increasing prevalence of knee OA, the disabling variant of arthritis examined in Dr. Zbehlik's research.

Many adults with knee OA do not exercise, although data strongly supports exercise for pain relief in this population (Messier et al., 2013). Weight loss also decreases pain significantly and can prevent progression of disease (Felson et al., 1997). However, there is a perceived gap in understand- 
ing among adults in the OA community about the benefits of exercise and weight loss in relieving OA pain. This gap may be a barrier to improving outcomes associated with this important public health matter.

To help inform a potential intervention, Dr. Zbeh-lik's research team sampled 100 adult volunteer respondents aged 40 years and older at Dartmouth-Hitchcock Medical Center in New Hampshire's rural Grafton County. Her seven-question survey was designed to determine awareness of the impact of weight loss and exercise on knee OA pain and assess interest in a tailored exercise program. This research was used as pilot data for a grant from the Hitchcock Foundation to design an exercise intervention for adults with knee OA.

As she approached the intervention design problem, Dr. Zbehlik began to question whether participant responses she had collected in New Hampshire were generalizable to other rural adults and if the data would reflect the fact that it had been collected in a state frequently ranked as one of the nation's healthiest. Dr. Zbehlik had become familiar with Dr. Ann Chester, the founding director of HSTA, through an informal online health forum Dr. Chester hosts. Dr. Zbelik met with Dr. Chester at West Virginia University (WVU), and the two discussed a possible collaboration to compare their respective rural populations with very different health outcomes.

Dr. Chester offered Dr. Zbehlik a possible pathway: collaborate with HSTA during the 2014-15 school year to include participants from West Virginia in her sample. Both researchers felt that HSTA's CBPR student project framework would provide an excel-lent opportunity to compare perceptions of knee OA and its treatments between two states: one ranked 3rd nationally in health outcomes in 2012 (New Hampshire) and one ranked 47th the same year (West Virginia), but both with largely rural and predominantly Caucasian populations (United Health Foundation, the American Public Health Association, Partnership for Prevention, 2012, United States Census Bureau, 2016). The result was a partnership that offered Dr. Zbehlik the opportunity to address questions about whether her original data was generalizable and portable, and gave HSTA students the chance to explore an important community issue while practicing their research skills in a highly structured setting.

What is HSTA? HSTA is a community-owned, community-run program that prepares underrepresented West Virginia high school students to pursue higher education and earn degrees in the health sciences and other STEM majors, thereby increasing the number of health practitioners and advocates in the medically underserved communities of the state (McKendall et al., 2014; Rye and Chester, 1999; Bardwell et al., 2009). Since it was founded in 1994, HSTA has grown from a nine-club program attended by 44 students and housed in two West Virginia counties into one that en- compasses 26 of the West Virginia's 55 counties, includes 80 clubs, and serves 800 students per year.

HSTA was founded on the belief that low expectationsnot lack of ability-present barriers to achievement for underrepresented students. Its leaders were confident that, given the opportunity, encouragement, and support, these students would excel in high school, post-secondary education, and their careers. This is supported by research (Marzano and Marzano, 2003; Newman et al., 1996; Schmoker, 2001) and underscored by 23 years of success realized by the program and its participants (Curtis et al., 2014; Branch and Chester, 2009; Bardwell et al., 2007; Branch et al., 2011; Branch et al., 2014).

HSTA students enter the program at the end of their eighth-grade year. HSTA staff recruit potential participants through presentations at local schools and community organizations, traditional media, social media, and other outreach efforts. Interested students submit applications, and completed applications are approved or denied by the local governing board that oversees each applicant's home region. These all-volunteer boards are made up of local representatives from the under-served community, education community, healthcare and other STEM industries, the HSTA student body, and HSTA parents (Chester and Dooley, 2011; McKendall et al., 2000).

Potential participants are vetted on need, potential to succeed, and interest in STEM careers. They must also meet at least one of four eligibility criteria (self-identified): African American, rural, financially dis-advantaged (free or reduced-price lunch), and/or first-generation to college (neither parent holds a college degree). Most students meet two or more of these criteria. Of the students currently enrolled in the program, 37\% are African American, 46\% are financially disadvantaged, $68 \%$ are first generation to college, and $75 \%$ are rural (Figure 1). Although gender is not a criterion for admission, $69 \%$ of HSTA's students are female.

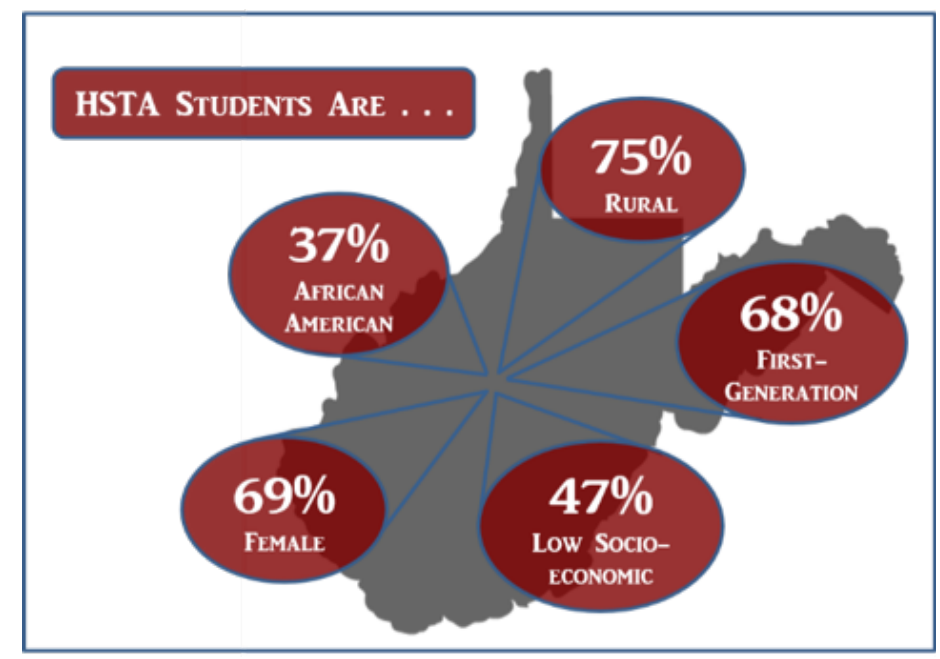

Figure 1. HSTA serves students from West Virginia populations that are underrepresented in STEM fields. 
HSTA students matriculate through the program in grades 9-12. HSTA requires a 2.5 GPA for acceptance and a 3.0 GPA for continuation in the program (grades 10-12). To complete the program, students must participate in their local HSTA after-school club, achieving a $70 \%$ attendance rate per semester, meet rubric requirements in completing four research projects (one per year) and presenting their results at HSTA's annual Science Symposia, attend two HSTA summer camps, complete 75 hours of community service, and adhere to all behavioral policies.

As HSTA developed over time, it became clear that students mastered academic skills more effectively when they participated in projects that directly influenced their family and friends. Thus, CBPR became a central component of the curriculum.

In weekly club meetings held throughout the school year, students develop CBPR-based research projects that examine issues relevant to them and their communities. Under the instruction of HSTA teachers, field site coordinators, community research associates (CRAs), and local and long-distance STEM professionals, students engage in authentic scientific methodologies: problem identification, question formation, background research, formulation of hypothesis and null hypothesis, investigation, data collection, and analysis. HSTA students use the nine principles of CBPR to guide their projects:

1) Recognizes community as a unit of identity

2) Builds on strengths and resources within the community
3) Facilitates collaborative, equitable involvement of all partners in all phases of the research

4) Integrates knowledge and intervention for mutual benefit of all partners

5) Promotes a co-learning and empowering process that attends to social inequalities

6) Involves a cyclical and iterative process

7) Addresses health from both positive and ecological perspectives

8) Disseminates findings and knowledge gained to all partners

9) Involves long-term commitment by all partners

Table 1 shows examples of standard, student-run HSTA research projects from the 2014-15 school year.

Upon graduation from high school, students who have successfully completed all program requirements and continue to maintain an institution-specific requisite GPA at the college level, are eligible to receive an annual tuition waiver at nearly all West Virginia state-supported colleges and universities. Waivers are available to students for both undergraduate and graduate work, including terminal professional degrees in STEM. These waivers help many HSTA alumni complete intensive education programs without the burden of substantial tuition debt. Political and financial support for HSTA is reflected in a budget allocation and tuition waiver provision by the West Virginia legislature.

As of May 2017, 2,556 high school students had completed the HSTA program. Among the 2016 HSTA alumni

Table 1. Example student-designed HSTA research projects from the 2014-15 school year (not based on the Dartmouth-HSTA project)

\begin{tabular}{lll}
\hline Research Question & Hypotheses & Results \\
\hline & $\begin{array}{l}\mathrm{H}^{1} \text { : Visual acuity will be affected by different stages of light- } \\
\text { Would differences in lighting affect the }\end{array}$ & $\begin{array}{l}\text { ing. } \\
\text { results of a visual acuity test? }\end{array}$ \\
& $\begin{array}{l}\mathrm{H}^{\mathrm{O}} \text { : There will be no difference in the results of the visual } \\
\text { acuity tests, no matter the intensity of the lighting. }\end{array}$ & $\mathrm{H}^{1}$ is accepted \\
\hline
\end{tabular}

Are suicidal thoughts more common in males or females on the Facebook community?

Can an intervention increase teen knowledge of the effects of drug and alcohol on pregnancy?
$\mathrm{H}^{1}$ : Females are more likely to have thoughts of suicide.

$\mathrm{H}^{\mathrm{O}}$ : The gender of the participants does not affect the number of thoughts of suicide.

$\mathrm{H}^{1}$ : Students will have increased knowledge of the effects of drugs and alcohol on pregnancy after the intervention.

$\mathrm{H}^{\mathrm{O}}$ : The intervention will not increase the knowledge of the students in the study

$\mathrm{H}^{1}$ : If the students participate in 2 or more sports, then they will have a lower BMI. BMI of the students who participate in two or more sports when compared to those who participate in less than two?
$\mathrm{H}^{\mathrm{O}}$ : Regardless of the number of sports the students participate in their BMI will not be affected.
T-test $\mathrm{p}$ value $=0.474789529$

$\mathrm{H}^{\mathrm{O}}$ is accepted

T-test $\mathrm{p}$ value $=0.65788253$

$\mathrm{H}^{\mathrm{O}}$ is accepted

T-test $\mathrm{p}$ value $=0.021004415$

$\mathrm{H}^{1}$ is accepted
Are people in rural regions more stressed than people in urban regions?
$\mathrm{H}^{1}$ : People who live in urban areas will be more stressed.

$\mathrm{H}^{\mathrm{O}}$ : There will be no difference between the areas.
T-test $\mathrm{p}$ value $=0.088064$

$\mathrm{H}^{\mathrm{O}}$ is accepted 
college freshmen, 99\% matriculated to college compared to $55 \%$ of West Virginia's general-population high school graduates (West Virginia Council for Community and Technical College Education, West Virginia Higher Education Policy Commission, 2017) and $69.7 \%$ of U.S. general-population high school graduates (United States Bureau of Labor Statistics, 2017). Of the HSTA alumni who have gone on to higher education since the program's foundation, $87 \%$ have completed a four-year degree or higher. This number contrasts with $48.2 \%$ of in-state and out-of-state first-time freshmen seeking a bachelor's degree at any West Virginia college or university (cohorts 2006-2010) who graduate within six years (West Virginia Higher Education Policy Commission, West Virginia Council for Community and Technical College Education, 2017). The national proportion of fall 2007 first-time, full-time bachelor's degree-seeking undergraduates at public U.S. institutions who graduated within six years was $57.7 \%$ (West Virginia Higher Education Policy Commission, West Virginia Council for Community and Technical College Education, 2017). In addition, 64\% of HSTA alumni are enrolled in or have graduated from STEM programs, compared to WV STEM degree rates of $18 \%$ (Wright, 2017) and the proportion of overall degrees in science and engineering at the national level, which was $28.9 \%$ in 2010 (West Virginia

Higher Education Policy Commission, West Virginia Council for Community and Technical College Education, 2017) (Figure 2). Once in the workforce, HSTA alumni earn, on average, $\$ 30,000$ more per year than their highest-earning parent (Chester and Dooley, 2011).

\section{METHODS}

The Dartmouth-HSTA study was designed by Dr. Zbehlik to identify beliefs of adults over 40 in rural settings about knee OA pain, exercise, and weight loss and how they may differ between New Hampshire and West Virginia populations. HSTA leader-ship of the project was taken on by one of the pro-gram's four CRAs, HSTA staff who provide a conduit between professional researchers and the students, teachers, and community members participating in HSTA research projects (see a full description of the CRA role below under "The CRA Component").

Per standard HSTA protocol, the lead CRA presented the project parameters to the HSTA Joint Governing Board, which oversees HSTA at the state level, to obtain permission to carry out the research. Such permissions are required for all outside research projects. Exemption was obtained through the Commit-tee for Protection of Human Subjects of Dartmouth College.

Once all approvals were in place, Dr. Zbehlik provided project materials - survey tool, data collection matrix, and study protocol - to the lead CRA, who in turn provided them
HSTA Students Achieve High Rates of Matriculation, Graduation, and Pursuit of STEM Careers

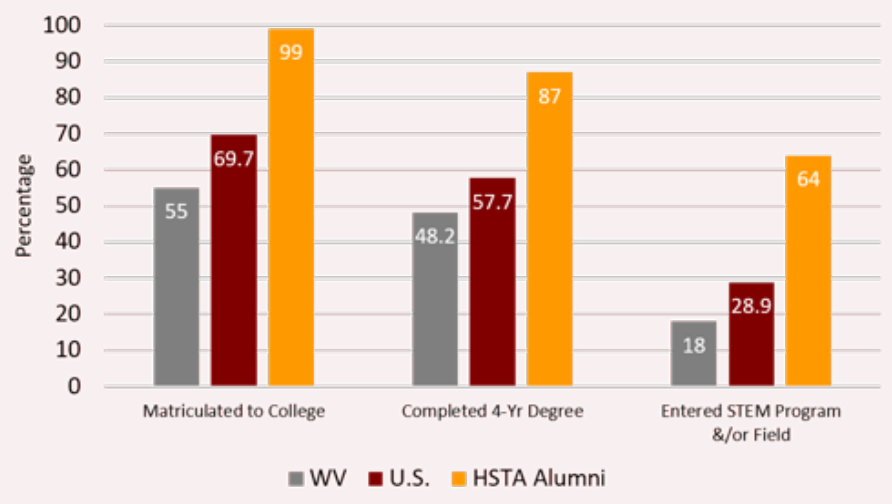

Figure 2. HSTA students achieve higher rates of matriculation, graduation, and pursuit of STEM fields than their general-population peers. Data retrieved from West Virginia Council for Community and Technical College Education, West Virginia Higher Education Policy Commissions, Community and Technical College System of WV (2017); WV Higher Education Policy Commission, Community and Technical College System of WV (2017; United States Bureau of Labor Statistics (2017); Wright, 2017).

to the CRA team. The piloted opinion survey included seven agree-disagree questions regarding adults' experience with knee pain, knowledge of knee OA treatments, and interest in engaging in a tailored exercise program. A fill-in-the-blank section requested self-reported age, gender, height, and weight. The CRA team distributed materials to 34 students participating in the project, their teachers, and their regional field site coordinators - managerial HSTA staff that oversee the 14 regions into which HSTA is divided and provide administrative, logistical, and educational support to HSTA clubs, students, and teachers within their regions. Students received standard ethics training from their regional CRAs, and training on study protocol and data collection from their CRAs, field site coordinators, and/or teachers. Quality control and consistency in protocol training was overseen by the CRAs via direct involvement and frequent communications with students and fellow staff. CRAs, field site coordinators, and teachers also worked together to ensure students' understanding of the importance of adhering to protocol to generate valid data. The students took that responsibility seriously in carrying out their data collection.

With the support of their adult HSTA leaders and in many cases family members, participating HSTA students spanned out across their communities to identify survey respondents, and collected data from a convenience sample of adults aged 40 and over with and without knee pain using the inclusion criteria, script, and survey instrument provided by Dr. Zbehlik. Exempted research designation required anonymous participation. Participation was voluntary and no protected health information was gathered.

As they collected their surveys, students entered the data 
into one of four password-protected Excel spreadsheets. Students worked in teams of two, with one student entering data and a second student checking the data after it was entered. Students then traded roles and conducted a second quality check, sometimes with the assistance of a third student, teacher, or field site coordinator. As each spreadsheet was completed, it was forwarded to the lead CRA for aggregation, a final quality check and cleaning, and provided to Dartmouth. Once the new West Virginia data were combined with the New Hampshire data previously collected, both Dr. Zbehlik and HSTA students received the cross-state dataset ready for analysis, with HSTA bound by an agreement of first publication protection for Dr. Zbehlik.

Before collecting data, students identified research questions based on the pilot survey. Once the data were collected, they analyzed the complete cross-state dataset to support or reject their hypotheses. They presented their results at the 2015 HSTA Science Symposium in accordance with HSTA program requirements. A total of 17 projects were presented by both individual students and teams.

\section{RESULTS}

The original intent of the West Virginia portion of the Dartmouth project was to collect baseline data for comparative analysis via a minimum of 100 surveys, on par with the number of responses gathered in the original survey conducted in Grafton County, New Hampshire. HSTA students, however, were able to gather 1,129 unique surveys over nine months from 17 West Virginia counties. HSTA students' ability to gather data far surpassed Dr. Zbehlik's expectations. An examination of the mutual benefits realized by Dr. Zbehlik and her student partners is informative in this setting.

HSTA as a powerhouse of data collection. Dr. Zbeh-lik was impressed by the sheer power of the HSTA data collection mechanism: a group of motivated, focused high school students under the guidance of trained teachers and staff that effectively functioned like a fiber-optic cable into hard-toreach populations. She had encountered limitations to efficient commu-nity-based data collection for her pilot study; the best option available for the convenience sample was to collect surveys locally rather than to drive through-out the state to gather data. HSTA, having a far-reaching program already in place, facilitated the research and helped increase participation because people in the communities knew the program and its students, were willing to listen and wanted to help.

Building trust is key. A sustainable program like HSTAone that does not come and go as a project is begun and ended-makes a difference at the heart of the community. HSTA has been working in West Virginia for 23 years, so communities know the pro-gram and are accustomed to interacting with its students. In addition, HSTA has bolstered the number of healthcare professionals in the state while also cultivating lasting relationships within communities (Johns, 2012). HSTA is now in a position of having earned access to hard-to-reach Appalachian populations through the trusting relationships it has built over the years. HSTA can carefully share this privileged access with outside researchers, and the students involved relied upon this foundation of trust within their communities to effectively gather their data.

Challenges of the sample size. From the HSTA perspective, the success of the survey data gathering was not a complete surprise, but it was much more information to manage than a standard student-run project would require. It also posed a logistics challenge: multiple students entering scores of survey results into four discreet spreadsheets, which then had to be compiled into a final matrix. Once students had entered and quality-checked the data, the lead CRA reviewed the data for redundancies and re-solved discrepancies as a procedural safeguard.

Subsequent to this study, HSTA researched and selected a web-based survey tool and data management system that has the capacity and flexibility to more efficiently capture, house, safeguard, and share the volume of data HSTA students have the potential to generate. Dartmouth has done the same. This plat-form has greatly eased data management and cooperative efforts at both institutions.

The HSTA timeline. Dr. Zbehlik not only found HSTA to be a powerful mechanism for data collection, but also a fast and efficient platform for conducting research and disseminating results, especially to the communities involved (Figure 3). Every year, HSTA students follow a program-prescribed schedule that begins with the design of their projects in the fall and ends with presentation at Science Symposium in the spring. Their progress and work are monitored by teachers, field site coordinators, and CRAs, and they are kept on track with interim deliverables and deadlines. This ensures that the research doesn't languish. Although the timeline presents some constraints, it also gives researchers an opportunity to collect data within a predictable framework.

Results are also certain and timely. HSTA students begin disseminating findings immediately during Science Symposia. They also frequently share their results with community partners and organizations that have supported their projects and by invitation from interested organizations throughout the state.

Student interactions with the project. For the students, the Dartmouth project differed from standard HSTA projects in three primary ways: sample demographics, sample population size, and prescribed research design and pro- 


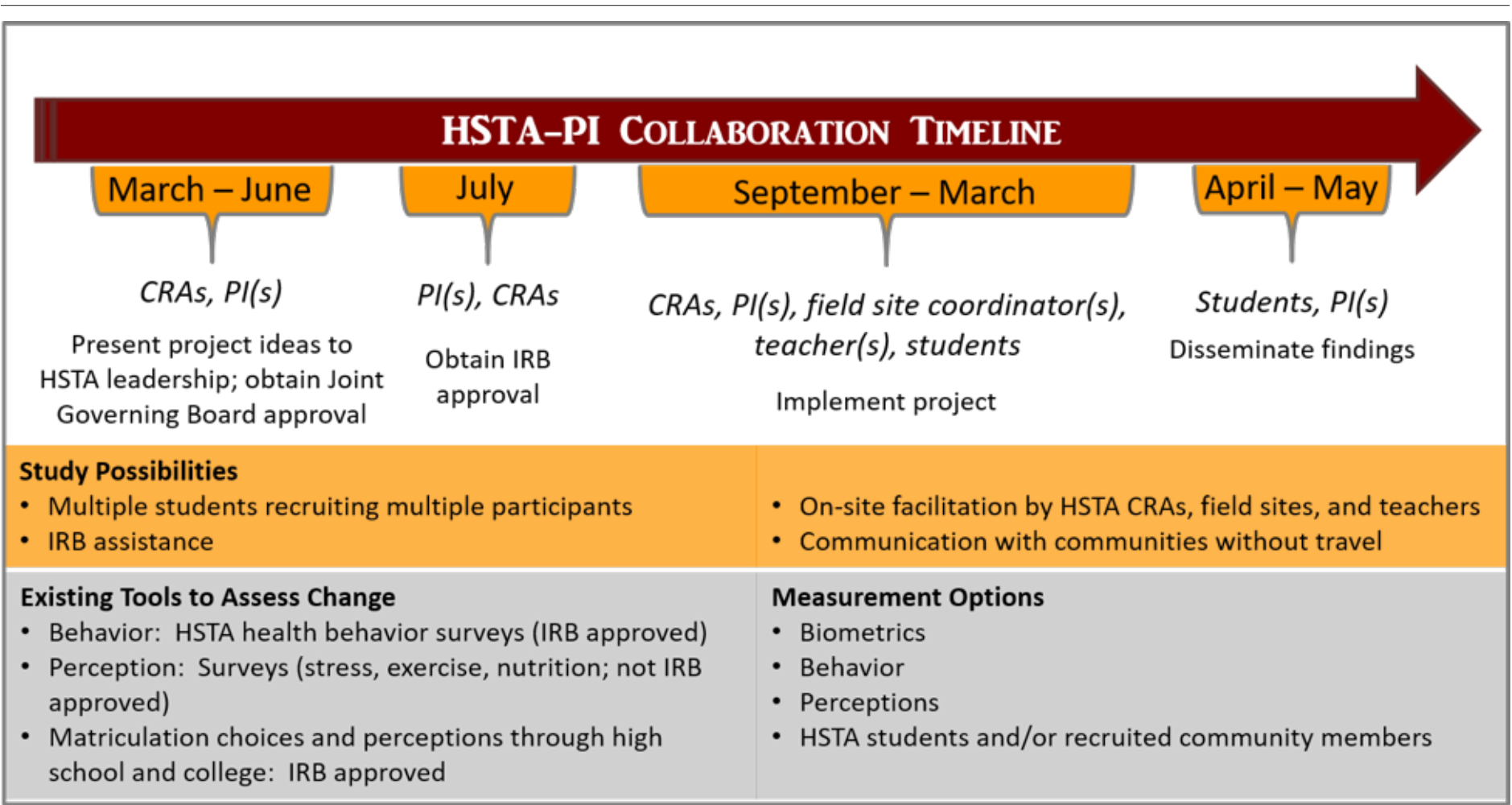

Figure 3. HSTA-PI Collaboration Timeline

tocol. The standard HSTA project is conceived, designed, and implemented by individual students, or sometimes two to three per-son teams at lower grade levels. In response to con-tent presented at summer camps and after school clubs, students raise questions about problems faced by their peers, families, and surrounding communities. Lines of inquiry expand to community knowledge, local environment, history, habits, and opinions, as well as potential solutions. Sample populations are usually accessible and familiar: fellow students, family, and adults HSTA students know through their day-to-day activities.

In contrast, an outside researcher designed the Dartmouth survey. It involved an age range that was significantly older than that of students and their peer groups. The sampling also demanded the students expand their population base beyond readily accessible family members, teachers, and other adult members of their social circles. The CRA team charged each student with collecting a minimum of 100 responses, and the project required strict adherence to prescribed protocols. To protect project participants and the quality and integrity of the data, the study protocol required no deviations from the script in requesting participation, delivering survey instructions, and collecting surveys.

The students had to use their problem-solving skills to meet requirements. Their methods of data collection included positioning themselves at grocery stores, pharmacies, and other locations frequented by older clientele. Students also ranged beyond the familiarity of their neighborhoods and towns, especially when they were located in isolated rural areas. They learned to approach potential respondents in a manner that would elicit a positive response to a request for cooperation in completing a survey. Most were able to memorize the scripting to affect a more natural conversational manner in their interaction with potential participants.

Although students could not deviate from the scripted protocols, they identified proper attire, most effective delivery and tone of voice, proper eye contact, and how to approach potential participants slowly, politely, and with a smile. They also devised an efficient two-person teaming system for entering and quality-checking the data entry to handle the large volume of responses received in conjunction with the data capture mechanism.

The project exposed the students to a basic aspect of research: the gathering of baseline data - professional on-thejob training - although it was sometimes met with resistance. Facing the unfamiliar requirement of the formal repetitive protocol, many students ex-pressed the frustration and discontent that can be typical to the age group: "This is boring!" HSTA teachers, field site coordinators, and CRAs helped their students navigate these challenges by talking through issues, supporting problem-solving efforts, and holding their ground: "The data isn't valid if you don't follow the protocol." At the end of the project, students presented successfully and reflected positively on the project. As one student commented, "In this project, I had to talk to older adults, and that taught me how to approach people." Another commented, "During this project, I learned how to assemble an IRB and use proper safety precautions when working with and testing people to protect their identity. It also taught me how to properly find a correct group sample and what ques- 
tions needed to be asked on other projects." A third added, "The best part of the study was seeing the how different the knowledge about osteoarthritis is between people above the age of 40 who live in New Hampshire and West Virginia. This taught me that people from different places in the United States can have different levels of knowledge on a particular health issue. I also learned about how to properly put together a research project. I am using that information now as a psychology major."

HSTA administration also recognize that an outside research design can diminish student involvement in some aspects of the research experience. In this case, students were not involved in survey or protocol design or IRB process. However, these limitations were coupled with opportunities. It provided students with a unique project for expanding their experience in collecting extensive baseline data, working with a professionally developed survey tool, and the ability to examine a binary-state population through a comparative data set. They were able to conduct their own studies of the data despite the lack of up-front involvement.

As they would with an individual project, they con-ducted background research, forming problem statements and research questions, used collected data to conduct analyses, and presented results (see Table 2).

\section{DISCUSSION}

Considerations for future partnerships. HSTA has a history of working with outside researchers and organizations. The Dartmouth-HSTA effort provides a recent example of the mutual benefits that can be realized from such partnerships. In the context of this project, it is useful to profile some of the unique characteristics of HSTA student-re- searcher projects for consideration by future collaborators.

The HSTA structure supports wide ranging partners and projects. Defining characteristics of the Dartmouth-HSTA project were the scale of the data collection effort, the multistate survey results, the participation by HSTA students from multiple clubs across several HSTA regions, and the sizable geographic area covered. Key lessons for students included why and how pilot surveys are conducted and techniques for following protocol, collecting and recording data, and protecting data fidelity and validity.

The flexibility of the program structure accommodates a wide range of research organizations, structures, and topics, so, like the Dartmouth collaboration, every HSTA partnership is singular. HSTA undertakes research opportunities with state and regional entities (Table 3). Collegial opportunities at West Virginia University, where HSTA has its fiscal, legal, and administrative home, often present themselves as well. For example, a two-year statewide effort was coordinated by the WVU School of Medicine and HSTA in which medical school residents developed an online survey instrument to isolate and measure the attitudes of students and their families about flu shots because of low participation in this preventative medicine. HSTA students delivered the survey on a school-wide basis under the direction of their CRAs and club teachers. In year one, like the Dartmouth project, students collected a large number of surveys - 2,559-which revealed personal and familial barriers to West Virginians receiving the vaccination, including perceived negative side effects and the motives of medical providers in promoting vaccinations to their patients. In year two, HSTA students used year one data to design and implement educational in-

Table 2. Example HSTA student projects based on the Dartmouth-HSTA project knee OA survey and cross-state dataset

\begin{tabular}{lll}
\hline Research Question & Hypotheses & Results \\
\hline & $\begin{array}{l}\mathrm{H}^{1} \text { : Gender does affect opinions about osteo- } \\
\text { arthritis because one gender may know more }\end{array}$ & T-test $\mathrm{p}$ value $=0.008918627$ \\
than the other. & $\begin{array}{l}\mathrm{H}^{\mathrm{O}} \text { : Gender does not have an effect on the } \\
\text { knowledge men and women have on osteoar- } \\
\text { thritis. }\end{array}$ & $\mathrm{H}^{1}$ is accepted \\
& &
\end{tabular}

$\mathrm{H}^{1}$ : There are significant differences in the understanding of osteoarthritis when comparing WV and New Hampshire residents.

Between community-dwelling adults aged 40 years and older in West Virginia and New Hampshire, are there significant differences in understanding of osteoarthritis of the knee, exercise, and weight loss?

Is there a difference between opinions of osteoarthritis/knee pain between the age groups of 40-50 years and 60-70 years?
$\mathrm{H}^{\mathrm{O}}$ : There are no significant differences in the understanding of osteoarthritis when comparing WV to New Hampshire residents.

$\mathrm{H}^{1}$ : People from the age group of $60-70$ years will have a stronger opinion about osteoarthritis/knee pain

$\mathrm{H}^{\mathrm{O}}$ : There is no difference
T-test $\mathrm{p}$ value $=.2275$

$\mathrm{H}^{\mathrm{O}}$ is accepted

T-test $\mathrm{p}$ value $=.415008$

$\mathrm{H}^{\mathrm{O}}$ is accepted 
tervention topics with guidance from participating medical school residents. The School of Medicine also made numerous presentations to local participants and their families to dispel misconceptions, and mitigate flu-shot resistance in response to the survey's findings. HSTA students also conducted a post-intervention survey and presented their results.

In another uniquely West Virginia collaborative, an arts and sciences doctoral study took an inside look at ginseng harvesting. Cured native West Virginia ginseng can be more valuable per ounce than gold in select markets. Locations of naturally occurring ginseng are closely guarded secrets because they provide much-needed income to rural harvesters with limited employment opportunities. The researcher, not a West Virginia native, would have been unable to access this small, intensely private population. Using the data collected by HSTA students, she examined techniques for locating and harvesting ginseng; knowledge and attitudes about legal and regulatory issues, environmental, sustainability, and safety practices; differences between wild and cultivated root; and the economics and brokerage interests involved. During the study, the researcher visited each of the participating clubs and taught students about the importance of ginseng to their own state and the handful of others that produce in the United States. She also provided her data for student projects and co-presented her findings with HSTA at the International Teacher-Scientist Partnership Conference.

The CRA component. HSTA's four community re-search associates, or CRAs, are the senior HSTA staff that make possible the scientific rigor that is a hall-mark of the HSTA program. Using combined expertise in research methodology and education methodology, they foster clear communication among students, teachers, researchers, and communities and help these groups work together effectively. CRAs are members of the communities in which HSTA operates. They are degreed in science, math, public health, and related fields, and they have experience in statistics, basic experimental design, curriculum and training design and measurement, institutional review board processes, and academic publishing. Of HSTA's current CRAs, three are former HSTA teachers; one of those three is also an HSTA alumni. Their base duties include: facilitating data collection for scientists engaged in CBPR; engaging scientists with HSTA students, families, and communities; facilitating the translation of research findings to communities; providing faculty with guidance on easy engagement in CBPR research; building capacity in communities for engaging in authentic research; and facilitating the reciprocal translation of community issues and problems to scientists and researchers. Within the HSTA structure, CRAs provide research support, IRB training, professional development training, and ongoing field support to HSTA teachers. They track student projects and approve/disapprove project designs and deliverables. They facilitate HSTA club networks across the state to enlarge the geographic area projects can cover, and they engage community STEM stakeholders and other resources in HSTA activities.

In HSTA project partnerships, the CRA team acts as the coordinating body for research, linking partners to HSTA administration, regions, clubs, students, and communities. When needed they assist in the conceptualization and formation of the project design. They formulate, submit, and track IRBs. They facilitate data-sharing among clubs, regions, and partners. They provide informal training to researchers, modeling engagement with young students in an academic environment and facilitating two-way researcher-student mentoring.

They also act as a communication conduit between communities and researchers to engender a mutually beneficial relationship through CBPR. The CRA role has become pivotal to the success of HSTA research partnerships.

IRB protocols involving minors. In the Dartmouth-HSTA project, participation by the convenience sample was voluntary and anonymous, no protected health information was gathered, and there was no intervention, so the study was designated as exempt from further IRB review. This saved time and simplified the application and data-collection processes.

HSTA projects involving consent, the collection of potentially sensitive information, physical contact with study subjects, etc., can require extensive preparation and expense due to the involvement of minors. In such cases, the IRB process becomes more complicated, and adult researchers or staff members may need to be directly involved in obtaining participant consent, monitoring interactions, ensuring data security, or other procedures. These types of factors have been accommodated in HSTA's research tenure. The CRA team regularly provides support to partnering researchers in formulating, submitting, and implementing required IRBs; HSTA teachers, volunteers, and other adult supporters can also be trained to provide needed assistance.

Studies involving HSTA students and other minors have taken place, but the Dartmouth study engaged the HSTA students as co-researchers, not as subjects of study in any way. There were no attempts by Dr. Zbehlik to measure changes in students resulting from their involvement in this project. To expand the population to a two-state focus, all other elements of the study needed to remain consistent with the initial New Hampshire sample.

Communication. Clear, timely communication is important to the conduct of a successful HSTA-supported project. This begins with project planning between HSTA and its partner researcher(s), including communications planning that will support the needs of the research body, HSTA staff, and HSTA students. As mentioned above, a pivotal relationship 
Table 3. Examples of partnerships that HSTA has entered into in recent years

\begin{tabular}{lll}
\hline Partner Organization & Study Type; Topic & Summary
\end{tabular}

West Virginia University (WVU)

Schools of Physiology and Pharmacology

WV Wise

WVU Extension

University of Pittsburgh, School of Clinical Pharmacology

WVU Schools of Medicine, Pharmacy, Dentistry, Nutrition, and Physical Activity and Sports Science, CPASS, Davis College

WVU School of Medicine

WVU Davis College of Agriculture, Natural Resources and Design

WVU Department of Geology and Geography

Friends of Blackwater

Marshall University

WVU Business School
Pilot intervention; the effect of a stress-reduction application software on user stress levels

Intervention; causes of and preventative measures for pregnancy and sexually transmitted diseases (STDs)

Pilot intervention; effect of cyberbullying prevention curriculum

Intervention; measuring family networking and lifestyle

Pilot intervention; effect of online social support platforms and a biomedical tracking device on lifestyle choices that impact physical health

Intervention; relationship between albumin levels and lifestyle choices and can levels be affected by lifestyle changes

Intervention; the impact of nutrition education on recipe choices and family time spent preparing meals

Prevalence study; psychosocial response to extreme flooding and its impacts on the community

Intervention; public understanding of global warming and climate change

Prevalence study; WESTEST 2 comparison among HSTA and non-HSTA students

Various; summer camp sponsor of local community health projects
100 participants; 26 HSTA students collected data over two years 2013-2015; researcher presented her research to students at annual symposium

$500+$ participants; HSTA students provided peer education on pregnancy and STDs; local board of education presentation and conference presentation by the students; oral presentation by HSTA Staff

117 HSTA students acted as participants; 16 students presented this data at the HSTA science symposium; conference presentation by researcher and HSTA Staff

2000 participants provided DNA samples, used a biomedical device to track physical activity and sleep, and kept a nutrition log; publication and poster session by the researcher

211 HSTA student and family participants; three-year effort; students and researchers conducted biometric and psychometric pre-screenings, interventions via online support networks and biometric tracking, and post-screenings

Student-driven project; levels measured via blood sampling and lifestyle baseline established via survey year 1 ; educational intervention implemented year 2; 135 participants across WV; 19 HSTA students collected data

44 HSTA students delivered educational intervention to 15 fourth and fifth graders and parents

Hard copy surveys and video interviews of residents in the affected area; 10 HSTA students carried this project out with support from a WVU faculty member

Current HSTA students; presenting at local club and summer camp events

Historic WESTEST 2 scores for 336 anonymous high school participants were examined to determine differences between HSTA and non-HSTA students in a matched comparison that also looked at differences by gender and race

18 HSTA students have participated in this summer program and continue to work on their projects (e.g., drug take-back events; community garden); HSTA students have presented to WVU Rural Health Scholars about drug take-back events 
exists between researchers and CRAs, with the CRAs facilitating understanding between the realms of science and education, streamlining the partnership process, and ensuring that issues are addressed in a timely manner. Researchers can also work directly with field site coordinators, teachers, and students as time and structure allow. Team communications always begin with the project's presentation by HSTA staff to the HSTA Joint Governing Board. They continue among team members with mode, frequency, and team member involvement being dictated by project structure and individual needs and availability.

Communication is also important to HSTA's young learners, who develop a sense of belonging to the research team when they are in contact with their partners. As novice researchers, they need direction, information, constructive feedback, positive reinforcement, and the opportunity to share their own experiences and the perspective of their communities in relation to the issues being addressed. When HSTA students feel well supported, they can more confidently face difficult tasks and unfamiliar processes and enjoy an enriching learning experience.

Thus, it is preferable that partnership projects include a structure through which students can easily communicate with their fellow researchers. In past projects, including the Dartmouth study, various elements have been used to create such a structure. Re-searchers have engaged in regular meetings with students, handled live or via telephone or video-conferences. Researchers have also conducted workshops, appeared as guest speakers at club meetings and summer camps, presented final project results to their teams, and attended student project presentations. Project teams have employed electronic means of communication, including e-mail and social media platforms, and CRAs have consistently acted as an avenue for the transmission and translation of information. The primary element of all of these interactions is a mutually agreed process that is workable for the researcher and that provides students with input in a predictable and timely manner.

It is also worth noting that researchers and the communities in which HSTA operates can realize mutual benefits of communication. Through HSTA partner-ship projects, researchers have the opportunity to listen to community issues and learn more about challenges faced by populations of interest. They can also facilitate educational programs, conduct interventions, and engage in longitudinal research that can better serve the needs of subject populations.

Mentoring. HSTA is first and foremost a STEM education program, and mentoring is a key component of its students' experience. Constructs of observational learning and peer modeling as well as Social Development Theory indicate that social interaction is not only crucial to cognitive development but also a means of knowledge acquisition through modeling and peer observations (Ladson-Billings, 1994). Because social support is key to student achievement and self-worth (Vygotsky and Cole, 1978), HSTA surrounds students with opportunities for social interaction as well as peer and adult modeling.

Almost every activity students participate in provides intentional mentoring or mentoring by example through a vast network of people who provide guidance and model success - teachers, field site coordinators, CRAs, college faculty and staff, community members, research scientists, family members, and near-peers (college students and recent HSTA alumni). Someone is always available to provide social support and academic guidance. Students with similar goals also work together in mentoring "posses" in HSTA clubs and camps. Bonding with like-minded peers is a powerfully motivating experience (Vygotsky and Cole, 1978), and having both a safe space to gather and a group of friends with similar goals makes breaking ingrained cultural barriers easier (Ladson-Billings, 1994).

Researchers who partner with HSTA should consider integrating a mentorship component into their project designs. Personal interaction with researchers through meetings, workshops, the mutual undertaking of project tasks, and even simple e-mail exchanges help students go further in developing their skills. Such interactions offer many benefits to students: in-creased rigor of research activities, involvement in more refined research with stricter protocols, contact with STEM professionals to whom they would not have access via in-school time or non-HSTA extracurricular activities, the opportunity to network within the professional STEM community, ability to collaborate across city, county, and regional borders, and greater opportunity to be published. HSTA CRAs can play a significant role in fostering student-researcher relationships by helping the team incorporate mentoring activities into the project plan, providing guidance to outside researchers in how to effectively interact with students, and acting as a communication bridge between researchers and students.

Because Dr. Zbehlik's research design and instrumentation were already in place at the time the Dartmouth-HSTA project was implemented, and she was under unusual time and distance constraints, her project did not include a mentoring component. However, in future efforts, her preference would be to work directly with the HSTA student body: "Having the students be part of the design from the be-ginning would be optimal and could really inform the work."

\section{Creating a bridge between STEM education and STEM} professionals. HSTA is a historically successful STEM education program for underrepresented youth in their formative years that has developed a unique capability to partner its students with STEM professionals in conducting handson research with aspects of CBPR as a foundation. Over the 
course of two decades, HSTA has built many bridges between nascent researchers and experienced scientists.

The Dartmouth-HSTA project exemplifies the type of successful study that can be undertaken through the program. The expansive data collected by HSTA students under the auspices of Dr. Zbehlik-1,129 unique surveys in nine months across 17 West Virginia counties - demonstrates the powerhouse data collection mechanism inherent in the program's CBPR-based structure. It also illustrates the access HSTA students have to hard-to-reach rural populations via the trust the program has built with the communities in which it operates. Such access can help researchers learn more about the needs of these communities, formulate in-depth studies to explore those needs, generating meaningful and, when needed, expansive data, and implement interventions. From the students' perspective, partnerships like the Dartmouth-HSTA project allow them to engage in professional research and hone the research skills they learn throughout their time in the program. Such opportunities contribute to the high matriculation, graduation, and STEM participation rates realized by HSTA alumni.

HSTA has entered into collaborations with outside individuals and organizations since its foundation in 1994, and its structure supports wide-ranging partners and projects. HSTA staff are trained to support the types of research-education projects carried out by the program, with HSTA CRAs providing the primary conduit among program participants, other HSTA staff, and external collaborators. Researchers can work directly with students to encourage STEM participation in populations underrepresented in such fields while getting an in-depth look at challenged communities. Partnership research is propelled by the HSTA research time line, and results are quickly disseminated to the communities in which they are conducted. HSTA can also provide outside researchers access to quantitative program data for examination and comparative analysis, as well as specialized evaluative instruments to analyze that data.

After the conclusion of her project, Dr. Zbehlik commented, "HSTA is a powerful mechanism for data collection and a fast and efficient platform for conducting research, especially bringing results back to the community. This is a great HSTA bonus. I look to the program as having great potential to develop public health interventions, as well." The authors encourage researchers and others interested in providing gateways to the STEM pipeline for underrepresented populations to consider the possibility of future partnerships with this far-reaching precollege STEM intervention program.

\section{AUTHOR INFORMATION Corresponding Author}

Ann L. Chester, Director, Health Sciences and Technology Academy, P.O.Box 9026, Room 3023 HSC, Morgantown,
WV 26506-9026

\section{Author Contributions}

The manuscript was written through contributions of all authors. All authors have given approval to the final version of the manuscript.

\section{FUNDING SOURCES}

This work was supported by the National Institutes of Health (R25OD010953-04, R25A1098781- 01A1)

\section{ACKNOWLEDGMENTS}

Bascom-Slack, Liz Genné-Bacon, Katherine Malanson and Revati Masilamani, who provided insightful comments on the manuscript.

\section{ABBREVIATIONS}

CBPR: community-based participatory research; HSTA: Health Sciences and Technology Academy; STEM: science, technology, engineering and mathematics; OA: osteoarthritis; CRA: community research associate.

\section{REFERENCES}

Bardwell, G., Morton, C., Chester, A., Pancoska, P., Buch, S., Cecchetti, A., Vecchio, M., Paulsen, S., Groark, S., and Branch, R. (2009). Feasibility of ado-lescents to conduct community-based participatory researh on obesity and diabetes in rural Appalachia. Clinical Translational Science, 2(5), 350-354.

Bardwell, G., Mujuru, P., Fitch, C., Seidel, G., Hu, W., Sogodogo, K., and Chester, A. (2007). Engaging youth to examine lifestyle behaviors through authentic research with university partnerships. The International Electronic Journal of Health Education, 10, 95-103.

Branch, R. and Chester, A. (2009). Community-based participatory clinical research in obesity by adolescents: Pipeline for researchers of the future. Clinical Translational Science, 2(5), 340-349.

Branch, R., Chester, A., Hanks, S., Kuhn, S., McMillion, M., Morton McSwain, C., Paulsen, S., Para, U., Cannon, Y., and Groark S. (2014). Obesity management organized by adolescents in rural Appalachia. Obesity Interventions in Underserved Communities: Evidence and Directions, 205213.

Branch, R., Chester, A., Morton-McSwain, C., Al Ayubi, S., Bhat Schelbert, K., Brimson, P., Buch, S., Cannon, Y., Groark, S., Hanks, S., Nukui, T., Pan-coska, P., Parmanto, B., Paulsen, S., and Wahl, E. (2011). A novel approach to adolescent obesity in ru-ral Appalachia of West Virginia: Educating adolescents as family health coaches and research 
investigators. In M. Zimering (Ed.), Topics in the Prevention, Treatment and Complications of Type 2 Diabetes. doi: $10.5772 / 23872$

Chester, A. and Dooley, E. (2011). West Virginia University's Health Sciences and Technology Academy. Journal of Higher Education Outreach and Engagement. 15(3): 8799.

Curtis, R., Smith, M., Moore, L., Georgieva, Z., Mathew, S., Chester, A., and McKendall, S. (2014). Rural student voices to improve educational attainment oriented programs. Journal of Behavioral and Social Sciences. 1(2), 66-73.

Felson, D.T., Zhang, Y., Hannan, M.T., Naimark, A., Weissman, B., Aliabadi, P., and Levy, D. (1997). Risk factors for incident radiographic knee osteoarthritis in the elderly: the Framingham Study. Arthritis Rheum. 1997;40, 728-733. Retrieved from http://onlinelibrary.wiley.com/doi/10.1002/ art.1780400420/abstract.

Israel, B.A., Schulz, A.J., Parker, E.A., and Becker, A.B. (1998). Review of community-based research: Assessing partnership approaches to improve public health. Annual Review of Public Health, 19, 173-202.

Israel, B.A., Schulz, A.J., Parker, E.A., Becker, A.B., Allen, A., and Guzman, J.R. (2008). Critical issues in developing and following CBPR Principles. In M. Minkler and N. Wallerstein (Eds.), Community-Based Participatory Research for Health: From Process to Outcomes (2nd ed., pp. 47-66). San Francisco: Jossey-Bass.

Johns, A. (2012). Hometown heros. WVU Health, 3(1), 2-5. Retrieved from https://issuu.com/wvuhealthcare/docs/ wvuhealth_spring2012

Ladson-Billings, G. (1994). What we can learn from multicultural education research. Educational Leadership, 51(8), 22-26. Retrieved from http://www.ascd.org/publications/educational-leadership/may94/vol51/num08/ What-We-Can-Learn-from-Multicultural-Education-Research.aspx

Marzano, R.J. and Marzano, J.S. (2003). The key to classroom management. Educational Leadership, 61(1), 6-13. Retrieved from: http: //www.ascd.org/publications/educational-leadership/sept03/vol61/num01/The-Key-to-Classroom-Management.aspx

McKendall, S.B., Kasten, K., Hanks, S., and Chester, AL. (2014). The Health Sciences and Technology Academy: An educational pipeline to address health care disparities in West Virginia. Academic Medicine, 89(1), 37-42. doi: 10.1097/ ACM.0000000000000047

McKendall, S., Simoyi, P., Chester, A., and Rye, J. (2000). The Health Sciences and Technology Academy: Utilizing pre-college enrichment programming to minimize post-secondary education barriers for under-served youth. Academic Medicine. 75(10): 121-123.
Messier, S., Mihalko, S., Legault, C., Miller, G., Nicklas, B., DeVita, P., Beavers, D.P., Hunter, D.J., Lyles, M.F., Eckstein, F., Williamson, J.D., Carr, J., Guermazi, A., and Loeser, R. (2013, September). Effects of intensive diet and exercise on knee joint loads, inflammation, and clinical outcomes among overweight and obese adults with knee osteoarthritis: The IDEA randomized clinical trial. Journal of the American Medical Association (JAMA), 310(12), 1236-1273. doi: 10.1001/jama.2013.277669

Newman, J., Brody, P.J., and Beauchamp, H.M. (1996). Teacher's attitudes and policies regarding play in the elementary schools. Psychology in the Schools, 33, 61-69. doi: 10.1002/(SICI)1520-6807(199601)33: $1<61: \quad$ : AIDPITS8>3.0.CO;2-Z

Schmoker, M. (2001). The results field-book: Practical strategies from dramatically improved schools. Alexandria, VA: The Association for Supervision and Curriculum.

Stranges, E., Ryan, K., and Elixhauser, A. (2011, January). Medicaid Hospitalizations, 2008. HCUP Statistical Brief \#104. Rockville, MD: Agency for Healthcare Research and Quality. Retrieved from http: //www.hcup-us.ahrq.gov/reports/statbriefs/sb104.pdf

Vygotsky, L. (1978). The role of play in development. In M. Cole, V John-Steiner, S. Scribner, \& E. Souberman (Eds.), Mind in society: The development of higher psychological processes (pp 92-104). Cambridge, MA: Harvard University Press.

United Health Foundation, the American Public Health Association, Partnership for Prevention. (2012). America's health rankings: A call to action for individuals and their communities. (2012 edition). Retrieved from http: //cdnfiles. americashealthrankings.org/SiteFiles/Reports/Americas-Health-Rankings-2012-v1.pdf

United States Bureau of Labor Statistics. (2017). College enrollment and work activity of 2016 high school graduates. Retrieved from https: //www.bls.gov/news.release/hsgec. nr0.htm

United States Census Bureau (Cartographer) (2016). White alone, percent, July 1, 2016 (V2016) [Demographic map]. Retrieved from https: //www.census.gov/quickfacts/fact/ map/US/RHI125216

West Virginia Council for Community and Technical College Education, West Virginia Higher Education Policy Commission (2017). West Virginia college-going rates by county and high school fall 2016. Retrieved from the West Virginia Council for Community and Technical College Education website: http: //www.wvhepc.edu/wp-content/uploads/2017/05/CGR-Report-2016.pdf

West Virginia Higher Education Policy Commission, Community and Technical College System of WV (2017). West Virginia higher education report 2016. Retrieved from the West Virginia Council for Community and Technical College Education website: http: //www.wvhepc.edu/wp-content/ uploads/2017/01/Report-Card.pdf 
Wright, J. (2017, September 1). STEM majors are accelerating in every state, just as humanities degrees are declining [Web blog post]. Retrieved from http: //www.economicmodeling.com/2017/09/01/stem-majors-accelerating-every-state-just-humanities-degrees-declining/ 